Cad. Benjaminianos, Belo Horizonte, v. 13, n. 2, p. 263-271, 2017

\title{
Entre uma seta e um círculo: algumas considerações sobre o tempo em Baudelaire
}

\section{An arrow or a circle: considerations about time in Baudelaire}

\author{
Alice Vieira Barros \\ Universidade Federal de Minas Gerais (UFMG), Belo Horizonte, Minas Gerais / Brasil \\ alicevieirabarros@gmail.com
}

Resumo: Este artigo objetiva construir uma leitura da poética de Baudelaire tomando como base a relação entre o "eu poético baudelairiano" e a História. Escolhi como principais aportes teóricos e ferramentas de leitura as reflexões do filósofo Walter Benjamin nas "Teses sobre o conceito de história", que são avessas a um historicismo tradicional e linear e possuem muitos pontos de tangência com as ideias baudelairianas, e o ensaísmo crítico da poeta russa Marina Tsvetáieva, com suas considerações a respeito da relação entre o "poeta e o tempo". Tencionamos desenvolver a hipótese segundo a qual a nostalgia do tempo mítico - por oposição a um tempo profano - configura, em Baudelaire, uma resposta crítica aos automatismos sobre a visão de progresso vigentes em seu contexto cultural, mediante a retomada consciente que o poeta faz de símbolos e mitemas da narrativa bíblica judaico-cristã.

Palavras-chave: Baudelaire; Mito; Modernidade; Walter Benjamin; Tsvetáieva.

Abstract: This paper aims to develop an analysis about Baudelaire's poetical works considering the connections between Baudelaire's lyrical subject and the History. I have chosen as the main theoretical sources Walter Benjamin's thoughts in the "Thesis of the Philosophy in History" which are opposite to the traditional historicism views and have a lot of similarities with Baudelaire's ideas, and also the critical essays of the Russian poet Marina Tsvetaeva and her considerations about the "poet and his time". We also aim to develop the hypothesis that the mythical nostalgia - as opposite to a profane time - constitutes, in Baudelaire, a critical answer to the automatisms of the ideas about progress which circulated in his cultural context, consciously recovering the symbols and mythemes of the Jewish-Christian biblical narrative.

Keywords: Baudelaire; Myth; Modernity; Walter Benjamin; Tsvetaeva. 
Não configura uma tarefa simples descrever a relação que a poesia de Baudelaire estabelece com a História. Dentre outros motivos, destaco o fato de que Baudelaire - enquanto poeta "moderno" e "antimoderno", nas palavras de Antoine Compagnon, não é um monólito. Tampouco poderiam configurar um monólito as vozes poéticas que constituem a sua poesia. Quem lê a poesia de Baudelaire sabe da existência de uma multiplicidade de vozes poéticas características das contradições da experiência humana na Modernidade. Uma outra dificuldade consiste mesmo na própria diversidade da fecunda produção artística de Baudelaire: de poemas em prosa a ensaios crítico, em alguma instância, a despeito da variedade dos gêneros, todos os textos baudelairianos revelam alguma pista sobre a maneira pela qual o poeta se relacionava com o seu tempo. Feitas essas ressalvas, no entanto, observo que esta maneira peculiarmente baudelairiana de se relacionar com o tempo e a História é transversal a toda a sua obra - das Fleurs du mal aos excertos aforísticos de Mon cour mis à nu.

Antes de sondar o que nos comunicam os próprios poemas de Baudelaire a respeito da sua relação com o tempo - a vida de Baudelaire "inventada pelos seus poemas", parafraseando o crítico Lawrence Lipking (LIPKING, 1981, p. 8) - é pertinente esboçar uma discussão sobre a relaçã entre os poetas em geral e a História. É claro que aqui não desejamos menosprezar as especificidades estéticas dos artistas, que fazem com que eles se portem com consciências críticas bastante distintas umas das outras com relação aos seus tempos históricos também muito distintos. Trata-se, na verdade, de um esforço de compreensão que se arrisca a utilizar arquétipos para pensar a condição órfica do poeta enquanto artista criador que se confronta com o seu tempo.

Para pensar esses arquétipos de poetas, recorro a um texto de crítica literária da poeta russa Marina Tsvetáieva intitulado Poetas com uma história e poetas sem uma história. Tsvetáieva constrói sua argumentação a partir desta tipologia de poetas. Os poetas "com história" são espécies de poetas que só podem caminhar para frente, e que se modificam tão profundamente pelos acontecimentos históricos que suas múltiplas existências poético-literárias não podem se reconhecer. Os poetas "sem história", por sua vez, são os poetas essencialmente "líricos", que conseguem, mediante um fino estro de manipulação da linguagem, tocar nos mesmos temas sem se tornarem monótonos, ou, dito de outro modo, dizer o mesmo "sem dizer o mesmo". Um exemplo interessante 
dessas categorias é a comparação que Tsvetáieva constrói entre os poetas Púchkin e Liérmontov. Cito Tsvetáieva, em tradução francesa da editora Éditions du Seuil:

Tandis que dans La Voile de Lermontov, alors âgé de dix-huit ans, il y a déjà Lermontov tout entier, ses émotions, offenses, duels, mort. Pouchkine jeune ne pouvait créer une telle Voile, et ce n'est pas du tout par manque du talent - il était tout aussi doué que Lermontov. C'est simplement parce que Pouchkine comme toute poète avec une histoire, tout comme l'histoire elle-même, a commencé par le tout début et a passé tout sa vie 'im Werden', tandis que Lermontov a existé d'un seul coup. Pouchkine pour se révéler a eu besoin de vivre non pas une vie mais cent. Et Lermontov pour se révéler, il lui a suffi de nâitre (TSVETÁIEVA, 1933, p.608). ${ }^{1}$

Cito este excerto do texto principalmente pela interessante entrada em Baudelaire que ele autoriza: se a revelação de Púchkin precisa de cem vidas para acontecer e a de Liérmontov já nasce pronta, o que poderíamos dizer a respeito do "eu poético" de Baudelaire que afirma de si mesmo - no início do Spleen número II: "Eu tenho mais lembranças do que se tivesse mil anos?". Ou quando, subvertendo todos os direcionamentos tradicionais da relação sujeito - objeto, no mesmo poema, afirma como uma verdade absoluta e universal no oitavo verso: "Eu sou um cemitério odiado pela lua"? Quem é esse "eu poético" e onde se localiza, estará mais próximo da revelação por um lampejo em seu tempo, como Liérmontov, ou, como Púchkin, precisaria de cem vidas para verbalizar suas lembranças infinitas? E, sobretudo, do que realmente se lembra este eu poético que sabe que não vive por mil anos, mas que consegue lembrar-se como se tivesse vivido?

A respeito da relação de Baudelaire com o tempo e a Modernidade - Veras afirma, em sua tese $A$ encenação tediosa do imortal pecado: Baudelaire e o Mito da Queda (2013) que Baudelaire responde ao

${ }^{1}$ Em 'La Voile' de Liérmontov, então com dezoito anos, havia já Liérmontov inteiro, suas emoções, ofensas, duelos, morte. O jovem Púchkin não poderia criar tamanho 'Voile', e não porque lhe faltasse talento - ele não era menos capaz que Liérmontov. É simplesmente porque Púchkin, como todo poeta que possui uma história, assim como a história ela-mesma, começou sua obra do início e passou toda a sua vida 'im Werden', enquanto Liérmontov existiu num só golpe. Púchkin para se revelar precisaria viver não uma vida, mas cem. E Liérmontov, para se revelar, bastaria nascer. Tradução nossa do francês que tenciona apenas facilitar a leitura do texto. 
primado da modernidade sobre as mais diversas esferas da vida agarrando-se à ruínas do passado. Veras lança mão da imagem do anjo de Paul Klee descrita por Walter Benjamin para descrever a relação de Baudelaire com o mundo moderno.

A princípio, pode causar alguma estranheza a analogia entre Baudelaire e a imagem do anjo de Paul Klee sobre a qual o filósofo Walter Benjamin reflete em uma das suas teses sobre o conceito de História. Isto porque, nas teses Benjamin deixa explícito como suas reflexões sobre o tempo e a Modernidade são tributárias de uma percepção materialista acerca do fluxo dos acontecimentos. As afirmações benjaminianas sugerem uma compreensão dialética das transformações históricas, segundo a qual uma narrativa historicista tradicional não é representativa do fluxo do tempo porque se submete à narrativa contada pelos vencedores, e não à narrativa da classe operária. $\mathrm{O}$ historiador adepto do materialismo histórico, para Benjamin, está ciente de que "todo monumento de cultura é também um monumento de barbárie". Dentre outros motivos, pelo fato de que as formas de circulação dos bens culturais no capitalismo industrial são massivamente excludentes.

Esta compreensão materialista dos acontecimentos por Benjamin parece ser a exata antípoda da maneira conservadora pela qual Baudelaire concebe a História e do horror baudelairiano à vulgarização proporcionada pelas formas democráticas de poder, bem como sua simpatia declarada pelos modos aristocráticos de ser e suas possibilidades de diferenciação - que a figura do dândi tenta reproduzir - num mundo burguês cada vez mais culturalmente homogeneizado.

No entanto, se nos detivermos com atenção no sujeito poético construído por Baudelaire em seus poemas e, sobretudo, na maneira como esse sujeito poético se relaciona com o "mito", será possível relativizar essa primeira impressão de que as compreensões da História de Benjamin e de Baudelaire estão em polos opostos. Sugiro, como ponto de partida, uma leitura atenta do poema "O Cisne". Em "O Cisne" é possível identificar de maneira muito clara a forma pela qual Baudelaire compreende a relação do poeta com o Mito e a História. Num poema dividido em duas partes, Baudelaire constrói um contraste interessante entre a vida mental e interior do poeta, e a vida da cidade moderna em mutação.

O primeiro verso inicia-se com uma invocação à figura mítica feminina de "Andrômaca" e, a princípio, poder-se-ia pensar que o poema trata desta questão mítica. No entanto, na medida em que avançamos 
na leitura, notamos que, paralelamente à evocação da imagem de Andrômaca, são descritos uma série de quadros parisienses que servem de testemunho sobre as intensas e rápidas mudanças pelas quais passou a capital francesa, cuja voracidade o sujeito poético parece ter dificuldades em acompanhar. Por isso, afirma: "Foi-se a velha Paris, a forma de uma cidade muda mais rápido que o coração de um mortal". Estas mudanças rápidas - telúricas, no compasso do coração dos mortais - parecem atormentar o poeta que, como um contrapeso, insiste na evocação da memória mítica de Andrômaca. Finalmente, Baudelaire constrói outra imagem - que também podemos chamar de "mítica", já que no próprio poema nomeada como "mito estranho e fatal".

O sujeito poético narra como um dia, quando a Paris mutante estava em plena efervescência do mundo moderno do trabalho e da circulação de mercadorias, o poeta avistou um "cisne", "Um cisne que escapara ao cativeiro". O desconforto do animal - que "no pó banhava as asas cheias de aflição" remete, imediatamente, a uma imagem anterior das "Flores do Mal" - a figura de exílio do albatroz, a que o poeta é comparado. Como o albatroz que parecia ridículo aos homens do convés, por ser "desengonçado" e alheio ao ambiente circundante, a imagem do Cisne contrasta-se vivamente com a dinâmica da cidade em transformação que o cerca. O Cisne, assim como Andrômaca, sugere a memória de um tempo mítico perdido e irrecuperável, com o qual se contrasta o tempo profano da História da modernidade, na qual o poeta encontra-se deslocado e destituído do caráter sacro que, na Antiguidade, se atribuía à figura do "vate".

Esta nostalgia baudelairiana do tempo mítico e, especialmente, de um passado mítico antes da expulsão do homem do Paraíso e da separação entre o homem e Deus, permite aproximar, de muitas maneiras, a compreensão baudelairiana da História com a forma benjaminiana pela qual o historiador deve se relacionar com o passado e com as ruínas. Sobre o anjo de Paul Klee, Benjamin afirma:

Há um quadro de Klee que se chama Angelus Novus. Representa um anjo que parece querer afastar-se de algo que ele encara fixamente. Seus olhos estão escancarados, sua boca dilatada, suas asas abertas. $\mathrm{O}$ anjo da história deve ter esse aspecto. Seu rosto está dirigido ao passado. Onde nós vemos uma cadeia de acontecimentos, ele vê uma catástrofe única, que acumula incansavelmente ruína sobre ruína e as dispersa a nossos pés. Ele gostaria de deter-se para acordar os mortos e juntar os fragmentos (BENJAMIN, 1940, p. 226). 
O exato ponto de tangência entre o anjo da história benjaminiano e Baudelaire reside na parte que se segue no texto, em que Benjamin menciona como esse anjo resiste a uma avassaladora tempestade que quer impelir seus olhos para o futuro, mas o anjo não consegue se privar de observar a pilha de ruínas e de voltar-se para o passado. Em ambos os casos está em xeque uma consciência crítica acerca da falência de uma ideia de progresso fundamentada exclusivamente no avanço da técnica.

É evidente que as respostas são bastante distintas. Dentre outros motivos pela grande distância que separa o pensamento filosófico da linguagem da poesia. A crítica de Baudelaire à ideia de progresso aparece de maneira explícita nos aforismos de "Meu coração à nu" e, ainda de acordo com Veras, tem mesmo raízes filosóficas, pois está fundamentada numa antropologia pessimista e na consciência da condição humana como inexoravelmente decaída. Qualquer avanço e melhora da humanidade num sentido moral só poderia ocorrer, de acordo com Baudelaire, na esfera individual. Isto está bastante distante da compreensão benjaminiana materialista da História - mesmo que esta visão dialética da História se distinga do marxismo vulgar e se mescle a um entendimento messiânico e teológico do fluxo do tempo. Mas Benjamin e Baudelaire se aproximam na consciência de que uma leitura linear e tradicional da História se mostra inviável. Assim como Baudelaire, a seu modo Benjamin também sabe dos males ocasionados pela instauração irreversível do tempo profano, por isso acredita que uma resposta salvífica para História atrela-se inevitavelmente a "arrancar a política das malhas do mundo profano".

Retorno, agora, à questão que propus no início desse texto. Como Baudelaire e sua poesia se posicionavam com relação ao seu tempo histórico? No início desse texto, parti de um ensaio da poeta russa Marina Tsvetáieva para apresentar dois arquétipos de poetas que se relacionam com o tempo de maneira oposta. De um lado, temos os poetas "com história", que são profundamente afetados em seu fazer poético pelo fluxo dos acontecimentos históricos. Do outro, os poetas líricos "sem história", que já nascem prontos e mantêm intactos os elementos de sua poesia, a despeito das transformações da História. É preciso que se observe, no entanto, que nenhum desses dois tipos de poetas habita fora da História. Não se pode fugir ao tempo e a História sem prejuízo de si mesmo e disso Baudelaire estava consciente.

Em primeiro lugar, é interessante observar que a postura nostálgica diante do Mito de Baudelaire está muito distante do que se poderia entender 
como uma compreensão alienada do tempo. Baudelaire estava totalmente cônscio do que a Modernidade representava para o poeta - e sua insistência na representação de mitemas, ou, como ainda esclarece Veras na mesma tese: a insistência de Baudelaire na reencenação da Queda e do mito adâmico - não é uma recusa à História e seria em algum nível absurdo colocar nesses termos a relação de um poeta com seu tempo.

Recorro, novamente, à poeta russa Marina Tsvetáieva, não mais em seu texto sobre os poetas com e sem história, mas ao ensaio $O$ poeta e o tempo. Desse ensaio, é possível extrair um trecho que poderia ser atribuído ao próprio Baudelaire: "O progresso? Mas até quando? E se progredíssemos até alcançar o fim do planeta - sempre para diante - até o abismo?". Esta desconfiança com relação à ideia de "progresso" é bastante afim à consciência crítica de Baudelaire que, como resposta à ilusória ideia moderna de progresso baseada apenas no avanço da técnica, apresenta a nostalgia do mito, a retomada do conceito de "pecado original" e, principalmente, do mito judaico-cristão da Queda. A consciência do "eu poético" baudelairiano, é, nesse sentido, bastante trágica e um tanto quanto fraturada. O sujeito poético de "O Cisne" sabe da impossibilidade da recuperação do tempo mítico perdido, que Paris seguirá com suas transformações no espaço urbano e, por isso, ele pensa, não somente em Andrômaca, mas em "qualquer um que tenha perdido o que não se recupera jamais".

A imagem do Cisne, conquanto evoque uma figura bela e aristocrática, impõe também seu caráter decaído, exilado e ridículo, por isso também comparável a uma série de figuras deslocadas do mundo moderno: "presos e vencidos". Esta solidão do poeta afastado de seu passado mítico é, de certa maneira, comparável à solidão do historiador benjaminiano, na medida em que, para desviar-se dos mecanismos dominantes de transmissão da cultura, precisa "escovar a história a contrapelo". A consideração baudelairiana a respeito da importância do mito para a cultura - e especialmente para o poeta e para a construção das singularidades da sua linguagem - pode ser aproximada da maneira pela qual Benjamin entende o fluxo do tempo e dos acontecimentos históricos, dando a atenção merecida às ruínas e ao que essas ruínas e fragmentos podem representar para "um tempo saturado de agoras", que não pode ser "homogêneo e vazio".

Em última instância, a metáfora base para caracterizar este "eu poético" baudelairiano e até mesmo para caracterizar o próprio Baudelaire 
enquanto poeta, é uma radicalização e um tensionamento dos símbolos que Tsvetáieva utiliza para representar o poeta lírico "sem história" e o poeta "com história". Para Tsvetáieva, o poeta lírico tradicional poderia ser representado por um círculo, devido à sua característica de voltar sempre ao mesmo tema, mas sem tornar-se monótono. Já os poetas com história poderiam ser representados por uma seta.

Nem uma seta nem um círculo, quando lidamos com Baudelaire (ou com o historiador benjaminiano que capta com sensibilidade a linguagem das ruínas) e com a consciência fraturada do sujeito poético que ele inventa em seus poemas, estamos diante, talvez, de uma seta, que, uma vez lançada, enviesou-se no atrito com o vento e entortou, espécie de intermédio entre seta e semicírculo. Trata-se, portanto, do jogo dinâmico e tenso entre a nostalgia do passado e da memória mítica e a consciência da impossibilidade de recuperação desse mesmo passado e de uma maneira sensível de relacionar-se com as ruínas, similar ao anjo da história benjaminiano.

A resposta crítica de Baudelaire a um tempo que se mira exclusivamente no futuro é a escuta do apelo do passado, em detrimento de sua recusa. Como Benjamin, Baudelaire sabe de tudo o que se perde com a negação do passado e do tempo mítico. Se, por um lado, não podemos retornar a um passado mítico perdido, a recusa do mito e a apologia do próprio tempo histórico vivido suprime uma dimensão importante da cultura e, de certa forma, até subordina a linguagem a usos que não comportam o desvio e a contingência da palavra poética.

Longe de uma resposta alienada ao fluxo da História, trata-se de uma resposta de consciência crítica e na desconfiança com relação à crença excessiva numa razão essencialmente cartesiana. Ao agarrar-se às ruínas, o Baudelaire artífice sabe que não está destituindo o artista de sua condição de "homem do mundo". Nenhum poeta poderia prescindir da História. Mas, como Tsvetáieva deixa claro em seu ensaio - fazer a apologia de seu tempo histórico não é uma boa resposta. Ou, melhor, não sendo nenhum poeta extemporâneo, caberia a Baudelaire, como a qualquer outro bom poeta, independentemente das tipologias, refletir seu tempo - mas não como um espelho. Antes, como um escudo (TSVETÁEIVA, 1932, p. 573). 


\section{Referências}

BAUDELAIRE, Charles. As flores do mal. Trad. Ivan Junqueira. Edições Nova Fronteira: Rio de Janeiro, 2006.

BENJAMIN, Walter. Magia e técnica, arte e política. Ensaios sobre literatura e história da cultura. Trad. Sérgio Paulo Rouanet. Brasiliense: São Paulo, 1987.

LIPKING, Lawrence. The life of the poet. The University of Chicago Press: Chicago, 1981.

TSVETÁIEVA, Marina. Récits et essais. Org. Verónique Lossky e Tzvetan Todorov. Trad. Nadine Dubourvieux, Luba Jurgenson e Veronique Lossky. Éditions du Seuil: Paris, 2009.

VERAS, Eduardo. A encenação tediosa do imortal pecado: Baudelaire e o Mito da Queda. 2013. 247 f. Tese (Doutorado em Estudos Literários), Faculdade de Letras, Universidade Federal de Minas Gerais, Belo Horizonte, 2013.

Recebido em: 24 de julho de 2018. Aprovado em: 25 de julho de 2018. 